\title{
DESKRIPSI KOMPETENSI PEDAGOGIK MAHASISWA CALON GURU PADA MATA KULIAH ANALISIS KURIKULUM MATEMATIKA
}

\section{DESCRIPTION OF PEDAGOGIC COMPETENCE OF PROSPECTIVE TEACHER IN MATHEMATICS CURRICULUM ANALYSIS}

\author{
Salwah Salwah ${ }^{1}$, Nur Wahidin Ashari ${ }^{2}$, Fahrul Basir ${ }^{3}$ \\ 1,2,3 Universitas Cokroaminoto, Jln. Latamacelling No.19 Kota Palopo 91913, \\ salwa_gama@yahoo.com, arhie_billingual@yahoo.co.id,fahrulmail2@gmail.com
}

\begin{abstract}
ABSTRAK
Penelitian ini adalah penelitian deskriptif dengan pendekatan kuantitatif. Tujuan dari penelitian ini adalah untuk mengetahui: (1) tingkat penguasaan kompetensi pedagogik mahasiswa dalam pengembangan kurikulum di sekolah, (2) tingkat penguasaan kompetensi pedagogik mahasiswa dalam penyelengaraan pembelajaran di kelas, (3) tingkat penguasaan kompetensi pedagogik mahasiswa dalam penguasaan karakteristik peserta didik, (4) tingkat penguasaan kompetensi pedagogik mahasiswa dalam pelaksanaan evaluasi pembelajaran. Subjek penelitian ini adalah 3 orang mahasiswa calon guru dalam mata kuliah analisis kurikulum matematika. Subjek dipilih berdasarkan tingkat akademik mahasiswa yang ditunjukkan melalui IPK mahasiswa. Teknik analisis data yang digunakan adalah (1) deskriptif persentase, (2) reduksi data, (3) penyajian data, dan (4) penarikan kesimpulan. Penelitian ini dilaksanakan pada semester ganjil tahun akademik 2018/2019. Hasil penelitian ini menemukan bahwa tingkat penguasaan kompetensi pedagogik mahasiswa calon guru dalam hal (1) pengembangan kurikulum di sekolah, (2) penyelengaraan pembelajaran di kelas, (3) penguasaan karakteristik peserta didik, (4) pelaksanaan evaluasi pembelajaran, rata-rata termasuk ke dalam kriteria menguasai.
\end{abstract}

Kata kunci: Kompetensi Pedagogik, Mahasiswa Calon Guru, Analisis Kurikulum Matematika

\begin{abstract}
This research was a descriptive research with qualitative approach. The aims of this research were to know : (1) mastery level of students' pedagogical competence in development of curriculum at school, (2) mastery level of students' pedagogical competence in conducting learning in class, (3) mastery level of students, pedagogical competence in mastering of students' characteristics, (4) mastery level of students' pedagogical competence in conducting earning evaluation. Subjects were 3 students of preservice teacher in mathematics curriculum analysis subject. Subjects were chosen based of students' academic level that showed through students' GPA. Techniques of data analysis were used are (1) descriptive of percentage, (2) data reduction, (3) data presentation, and (4) taking conclusion. This research conducted on odd semester academic year 2018/2019. The results showed that mastery level of of students' pedagogical competence of preservice teacher in (1) development of school curriculum, (2) conducting of learning in class, (3) mastering characteristics of students, (4) conducting learning evaluation, average of each involved in mastery criteria.
\end{abstract}


Keywords: Pedagogical Competence, Students of Preservice Teacher, Mathematics Curriculum Analysis

\section{How to Cite: Salwah, Ashari, N. W., \& Basir, F. (2019). Deskripsi Kompetensi Pedagogik Mahasiswa Calon Guru pada Mata Kuliah Analisis Kurikulum Matematika. Mathline: Jurnal Matematika dan Pendidikan Matematika, Vol.4, No.1, 75-84.}

\section{PENDAHULUAN}

Faktor yang mendukung dan menentukan kemajuan pendidikan dan kualitas peserta didik adalah guru. Guru yang dihasilkan dari suatu perguruan tinggi adalah seseorang yang akan menjadi tombak atau garda terdepan bagi keberhasilan sumber daya manusia. Di era revolusi industry 4.0 ini keberadaan guru tidak bisa tergantikan. Guru di era ini harus mampu mengusasi ilmu pengetahuan dan teknologi, agar dapat menghasilkan SDM yang unggul dengan kompetensi global. Selain itu, Guru juga harus mengusai 4 kompetensi, yaitu kompetensi pedagogik, professional, kepribadian dan sosial. Hal ini sejalan dengan pendapat Hakim (2015) yang menyatakan bahwa kualitas dari kompetensi mengajar guru memainkan peran penting dalam menciptakan dan membangun kualitas proses pembelajaran bagi siswa, dan juga menunjukkan level profesionalisme dari seorang guru.

Tuntutan guru saat ini sangat besar, karena di tangan merekalah akan tercipta insaninsan yang unggul baik nasional maupun international. Oleh karena itu, hal ini harus di mulai dari perguruan tinggi, khusunya perguruan tinggi yang akan menghasilkan caloncalon guru. Perguruan tinggi tersebut harus menghasilkan lulusan yang berdaya saing di era revolusi industry 4.0. mahasiswa calon guru dituntut harus mengusai keempat kompetensi guru yaitu kompetensi pedagogik, professional, kepribadian dan sosial. Hal ini sejalan dengan pendapat Purnomo (2017) yang menyatakan bahwa guru matematika dituntut dan diharapkan memiliki setidaknya empat kompetensi yaitu kompetensi pedagogik, kompetensi professional, kompetensi sosial, dan kompetensi kepribadian. Kompetensi pedagogik yang tertuang dalam Standar Nasional Pendidikan (Kurniawan \& Astuti, 2017) yaitu kemampuan mengelola pembelajaran peserta didik meliputi pemahaman terhadap peserta didik, perancangan dan pelaksanaan pembelajaran, evaluasi hasil belajar, dan pengembangan peserta didik untuk mengaktualisasikan ragam potensi yang dimilikinya.

Menurut Mulyasa (Kurniawan \& Astuti, 2017) kompetensi pedagogik sekurangkurangnya harus meliputi aspek-aspek: (1) pemahaman wawasan dan landasan 
kependidikan, (2) pemahaman terhadap peserta didik, (3) pengembangan kurikulum/silabus/RPP, (4) perancangan pembelajaran, (5) pelaksanaan pembelajaran yang mendidik, (6) pemanfaatan teknologi pembelajaran, (7) evaluasi hasil belajar, dan (8) pengembangan peserta didik untuk mengaktualisasikan ragam potensi yang dimilikinya. Menurut Putri \& Suwatno (2017) berpendapat bahwa kompetensi pedagogik meliputi memahami landasan wawasan dan kependidikan, memiliki kemampuan mengelola pembelajaran, memiliki pemahaman terhadap peserta didik, pengembangan kurikulum, perancangan dan pelaksanaan pembelajaran, evaluasi dan pengembangan peserta didik.

Menurut Suciu \& Mata (2011) Pusat Nasional untuk Formasi Guru dari Pendidikan Pra-academik telah mengembangkan 5 level kompetensi pedagogik dasar dari yang sederhana ke kompleks yaitu: (1) basic competence 1: memfasilitasi proses belajar mengajar inovatif yang berfokus terhadap siswa, (2) basic competence 2: memonitoring dan mengevaluasi hasil-hasil dari proses belajar mengajar, (3) basic competence 3: merencanakan dan menjalankan kurikulum, silabus, serta metode dan materi didaktik, (4) basic competence 4: membentuk partnership di dalam dan di luar sekolah, (5) basic competence 5: keterlibatan dalam proses pengembangan individu maupun pengembangan profesionalme.

Berdasarkan hasil Uji Kompetensi Guru (UKG) tahun 2017 diperoleh bahwa ratarata uji kompetensi guru masih di bawah nilai 70 dari skor maksimal 100. Hal ini sejujurnya bertentangan dengan tuntutan era revolusi industry 4.0 yang mana pendidik merupakan salah satu komponen pencetak sumber daya manusia berdaya saing global (Paramita, 2018). Oleh karena masalah-masalah yang telah dipaparkan tersebut, maka dirumuskan pertanyaan penelitian sebagai berikut: (1) Bagaimana tingkat penguasaan kompetensi pedagogik mahasiswa calon guru dalam pengembangan kurikulum di sekolah? (2) Bagaimana penguasaan kompetensi pedagogik mahasiswa calon guru dalam penyelengaraan pembelajaran di kelas? (3) Bagaimana penguasaan kompetensi pedagogik mahasiswa calon guru dalam penguasaan karakteristik peserta didik? (4) Bagaimana penguasaan kompetensi pedagogik mahasiswa calon guru dalam pelaksanaan evaluasi pembelajaran?.

\section{METODE PENELITIAN}


Penelitian ini merupakan penelitian deskriptif kuantitatif. Instrumen yang digunakan dalam penelitian ini adalah (1) lembar observasi kompetensi pedagogik, dan (2) pedoman wawancara. Teknik analisis data yang digunakan dalam penelitian ini adalah (1) deskriptif persentase, (2) reduksi data, (3) penyajian data, dan (4) penarikan kesimpulan. Subjek dalam penelitian ini adalah mahasiswa yang memprogram mata kuliah analisis kurikulum matematika. Dipilih 3 orang dari total mahasiswa yang memprogram mata kuliah tersebut. Ketiga subjek tersebut dipilih berdasarkan IPK mereka. Teknik analisis data yang digunakan adalah deskriptif dengan metode analisis adalah deskriptif persentase. Adapun klasifikasi kategori tingkat penguasaan kompetensi pedagogik yang digunakan dalam penelitian ini adalah:

Tabel 1. Klasifikasi penguasaan kompetensi pedagogik dari lembar observasi

\begin{tabular}{ccc}
\hline No. & Persentase (\%) & Kriteria \\
\hline 1 & $81,28 \leq x \leq 100$ & Selalu (sangat siap/sangat menguasai) \\
2 & $62,52 \leq x<81,28$ & Sering (siap/mengusai) \\
3 & $43,76 \leq x<62,52$ & Jarang (kurang siap/cukup mengusai) \\
4 & $25 \leq x<43,76$ & Tidak pernah (tidak siap/tidak menguasai) \\
\hline
\end{tabular}

Sumber: Modifikasi dari Nugraha (2013)

Ket:

$x$ : Persentase tingkat penguasaan kompetensi pedagogik

Penelitian ini dilaksanakan pada semester ganjil tahun akademik 2018/2019. Penelitian ini dilaksanakan pada matakuliah analisis kurikulum matematika. Mata kuliah analisis kurikulum matematika adalah matakuliah pilihan yang mengajarkan berbagai kurikulum telah diterapkan di Indonesia dan menelaah kurikulum yang diterapkan di Negara-negara yang memiliki tingkat pendidikan nomor satu di dunia. Pada mata kuliah ini mahasiswa calon guru juga diajarkan bagaimana kurikulum 2013 diterapkan di sekolah saat ini. Mahasiswa calon guru setelah memprogram mata kuliah ini akan memprogram mata kuliah magang yang merupakan mata kuliah praktek lapang yaitu mengajar secara langsung di sekolah. Oleh karena itu, agar tingkat pemahaman mahasiswa terhadap kurikulum 2013 semakin baik maka dosen pengampu mata kuliah memberikan tugas praktek mengajar matematika dengan penerapan K13 di kelas.

Prosedur penelitian adalah pertama mahasiswa calon guru yang memprogram mata kuliah analisis kurikulum matematika yang selanjutnya mendapat tugas final praktek mengajar dari dosen. Terpilih 3 mahasiswa dari seluruh mahasiswa yang memprogram mata kuliah tersebut, yang dipilih berdasarkan tingkat kemampuan akademiknya. Terpilihlah mahasiswa yang berkemampuan tinggi (MT), sedang (MS), dan rendah (MR). Ketiga mahasiswa tersebut diberikan angket kompetensi pedagogik, dosen matakuliah 
melaksanakan observasi dari praktek mengajar, dan melakukan wawancara terkait dengan angket dan hasil observasi yang telah dilaksanakan.

\section{HASIL DAN PEMBAHASAN}

Hasil wawancara dengan mahasiswa yang berkemampuan tinggi (MT), sedang (MS), dan rendah (MR) terkait dengan kompetensi pedagogik disajikan dalam tabel di bawah ini.

Tabel 2. Hasil Wawancara Per-aspek Kompetensi Pedagogik

\begin{tabular}{|c|c|c|c|}
\hline Aspek & MT & MS & MR \\
\hline $\begin{array}{l}\text { Pengetahuan tentang } \\
\text { kurikulum matematika } \\
\text { (apakah mahasiswa } \\
\text { memahami kurikulum apa } \\
\text { yang saat ini diterapkan, } \\
\text { dan apakah bisa } \\
\text { merancang perangkat } \\
\text { pembelajarannya? } \\
\text { Bagaimana anda yakin } \\
\text { bahwa perangkat yang } \\
\text { anda maksudkan sudah } \\
\text { sesuai dengan yang } \\
\text { seharusnya? } \\
\text { Bagaimana seharusnya } \\
\text { penerapan kurikulum } 2013 \\
\text { di sekolah itu?) }\end{array}$ & $\begin{array}{l}\text { 1. Memahami dan } \\
\text { mampu } \\
\text { merancang } \\
\text { perangkat } \\
\text { pembelajarannya. } \\
\text { Kurikulum yang } \\
\text { saat ini } \\
\text { diterapkan di } \\
\text { sekolah adalah } \\
\text { K13. } \\
\text { 2. Melalui mata } \\
\text { kuliah kami } \\
\text { diajarkan } \\
\text { bagaimana } \\
\text { penerapak K13 di } \\
\text { sekolah } \\
\text { bagaimana dan } \\
\text { bentuk perangkat } \\
\text { dan instrumen } \\
\text { yang seharusnya } \\
\text { digunakan saat } \\
\text { ini. } \\
\text { Melalui } \\
\text { Permendikbud } \\
\text { no. 20, 21, 22, } \\
\text { 23, dan 24 tahun } \\
\text { 2016. } \\
\text { 4eharusnya guru } \\
\text { tidak banyak } \\
\text { mengajar lagi, } \\
\text { namun hanya } \\
\text { sebagai fasilitator } \\
\text { bagi siswa. }\end{array}$ & 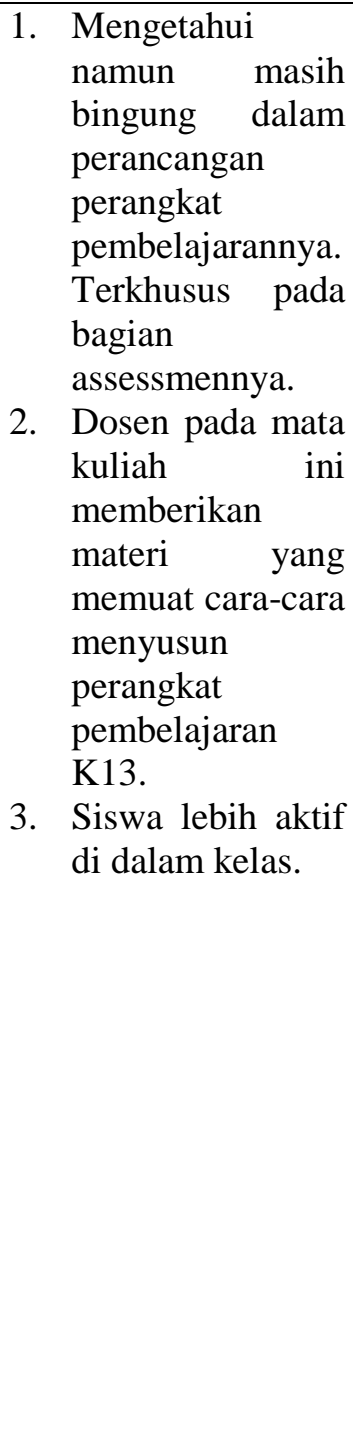 & 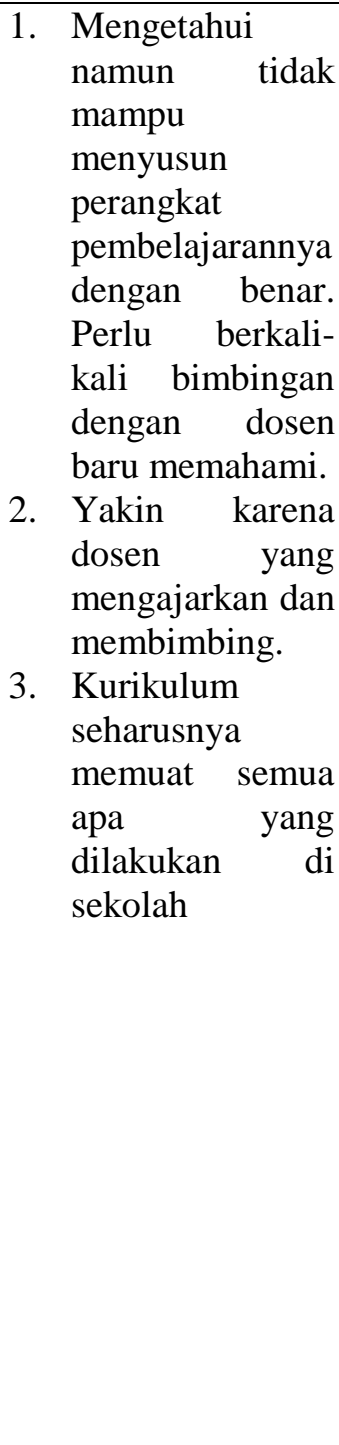 \\
\hline $\begin{array}{l}\text { Pengetahuan mengenai } \\
\text { strategi/pendekatan /model } \\
\text { pembelajaran } \\
\text { (apakah anda mengetahui } \\
\text { model/pendekatan/strategi } \\
\text { dalam mengajarkan } \\
\text { matematika? } \\
\text { Apakah mampu } \\
\text { mengaplikasikan }\end{array}$ & $\begin{array}{l}\text { Mengetahui beberapa } \\
\text { model seperti PBL, } \\
\text { Kooperatif dan } \\
\text { berbagai tipenya, } \\
\text { pendekatan seperti } \\
\text { pendekatan } \\
\text { kontekstual, } \\
\text { Scientifik, RME, } \\
\text { open ended, dan }\end{array}$ & $\begin{array}{l}\text { Hanya memahami } \\
\text { satu model } \\
\text { pembelajaran, } \\
\text { pendekatan } \\
\text { pembelajaran tahu } \\
\text { namun langkah- } \\
\text { langkahnya tidak. } \\
\text { Model kooperatif ada } \\
\text { beberapa yang bisa }\end{array}$ & $\begin{array}{l}\text { Hanya sedikit yang } \\
\text { saya tahu. } \\
\text { Menerapkan di kelas } \\
\text { pun, saya tidak } \\
\text { menguasai semua } \\
\text { langkahnya, hanya } \\
\text { yang umum saja } \\
\text { yang biasa dilakukan } \\
\text { guru di sekolah yang }\end{array}$ \\
\hline
\end{tabular}




\begin{tabular}{|c|c|c|c|}
\hline Aspek & MT & MS & MR \\
\hline $\begin{array}{l}\text { model/pendekatan/strategi } \\
\text { tersebut di dalam kelas?) }\end{array}$ & $\begin{array}{l}\text { strategi pembelajaran } \\
\text { seperti scaffolding, } \\
\text { namun dalam } \\
\text { pengaplikasiannya } \\
\text { tidak semua } \\
\text { dipahami. }\end{array}$ & $\begin{array}{l}\text { saya aplikasikan di } \\
\text { kelas yaitu model } \\
\text { kooperatif tipe NHT, } \\
\text { TPS, dan Jigzaw. }\end{array}$ & $\begin{array}{l}\text { saya ketahui seperti } \\
\text { ceramah. }\end{array}$ \\
\hline $\begin{array}{l}\text { Pengetahuan mengenai } \\
\text { pemahaman peserta didik. } \\
\text { (bila anda menjadi guru, } \\
\text { bagaimana anda } \\
\text { mengetahui bahwa peserta } \\
\text { didik mengalami } \\
\text { kesulitan? } \\
\text { Bagaimana cara anda } \\
\text { menangani kesulitan siswa } \\
\text { tersebut?) }\end{array}$ & $\begin{array}{l}\text { Bila saya menjadi } \\
\text { guru, untuk } \\
\text { mengetahui bahwa } \\
\text { siswa memiliki } \\
\text { kesulitan dari siswa } \\
\text { tidak bisa menjawab } \\
\text { LKS yang saya } \\
\text { berikan padahal } \\
\text { menurut saya LKS } \\
\text { tersebut sudah bagus. } \\
\text { Cara saya } \\
\text { mengatasinya dengan } \\
\text { memberikan } \\
\text { penjelasan sedetail } \\
\text { mungkin agar siswa } \\
\text { dapat memahami } \\
\text { maksud dari masalah } \\
\text { yang saya berikan. }\end{array}$ & $\begin{array}{l}\text { Bila siswa hanya } \\
\text { diam saja saat saya } \\
\text { bertanya. } \\
\text { Solusi yang saya } \\
\text { berikan adalah } \\
\text { membiasakan } \\
\text { bertanya ke siswa } \\
\text { dan membiasakan } \\
\text { mereka untuk } \\
\text { menjawab. }\end{array}$ & $\begin{array}{l}\text { Siswa merasa } \\
\text { kesulitan jika } \\
\text { mereka hanya diam } \\
\text { dan melamun saja. } \\
\text { Solusinya diberikan } \\
\text { pembelajaran yang } \\
\text { ada unsur } \\
\text { bermainnya. }\end{array}$ \\
\hline $\begin{array}{l}\text { Pengetahuan mengenai } \\
\text { assessmen pembelajaran } \\
\text { (apakah anda tahu } \\
\text { penilaian apa yang } \\
\text { digunakan di K13?) }\end{array}$ & $\begin{array}{l}\text { Ya mengetahui, } \\
\text { karena hal ini } \\
\text { dijelaskan di } \\
\text { permendikbud No.23 } \\
\text { tahun 2016. Di } \\
\text { lampiran peraturan } \\
\text { tersebut dijelakan } \\
\text { bahwa penilaian yang } \\
\text { digunakan adalah } \\
\text { penilaian autentik, } \\
\text { yang menilai } 3 \text { ranah } \\
\text { yaitu pengetahun, } \\
\text { sikap, dan } \\
\text { keterampilan. }\end{array}$ & $\begin{array}{l}\text { Ya tahu, penilaian } \\
\text { sikap, pengetahuan } \\
\text { dan keterampilan. }\end{array}$ & $\begin{array}{l}\text { Ya sedikit, yaitu } \\
\text { penilaian hasil } \\
\text { belajar. }\end{array}$ \\
\hline
\end{tabular}

Hasil pengamatan terhadap praktek mengajar siswa terait dengan kompetensi pedagogic adalah sebagai berikut:

Tabel 3. Rata-rata persentase kompetensi pedagogik mahasiswa calon guru 


\begin{tabular}{|c|c|c|c|c|c|c|}
\hline \multirow[b]{2}{*}{ Subjek } & \multicolumn{4}{|c|}{ Skor Per Aspek (\%) } & \multirow[b]{2}{*}{$\begin{array}{l}\text { Rata- } \\
\text { rata } \\
\text { Skor } \\
(\%)\end{array}$} & \multirow[b]{2}{*}{ Kriteria } \\
\hline & $\begin{array}{c}\text { Pemahaman } \\
\text { tentang } \\
\text { Kurikulum }\end{array}$ & $\begin{array}{c}\text { Pemahaman } \\
\text { tentang } \\
\text { Pelaksanaan } \\
\text { Pembelajaran }\end{array}$ & $\begin{array}{c}\text { Pemahaman } \\
\text { tentang } \\
\text { Peserta } \\
\text { Didik }\end{array}$ & $\begin{array}{c}\text { Pemahaman } \\
\text { tentang } \\
\text { Assesmen }\end{array}$ & & \\
\hline MT & 87.5 & 85 & 80 & 80 & 83,13 & $\begin{array}{c}\text { Sangat Siap } \\
\text { (Sangat } \\
\text { Menguasai) }\end{array}$ \\
\hline MS & 85 & 78.75 & 75 & 70 & 77.19 & $\begin{array}{c}\text { Siap } \\
\text { (Menguasai) }\end{array}$ \\
\hline MR & 66,25 & 65 & 70 & 65 & 66.56 & $\begin{array}{c}\text { Siap } \\
\text { (Menguasai) }\end{array}$ \\
\hline $\begin{array}{c}\text { Rata- } \\
\text { rata }\end{array}$ & 79.58 & 76.25 & 75 & 71.67 & 75.6 & Menguasai \\
\hline Kriteria & Menguasai & Menguasai & Menguasai & Menguasai & & \\
\hline
\end{tabular}

Pada Tabel 3 di atas dapat terlihat bahwa skor rata-rata mahasiswa dengan kemampuan akademik yang tinggi (MT) yaitu sangat siap (sangat menguasai) dengan kompetensi pedagogik. Rata-rata kompetensi pedagogik mahasiswa dengan kemampuan akademik sedang (MS) dan rendah (MR) adalah siap (menguasai) walaupun skor rata-rata kedua subjek tersebut berbeda jauh. Artinya untuk ketiga subjek calon guru matematika dalam aspek kompetensi pedagogik rata-rata masuk pada kategori siap mengelola pembelajaran dengan baik.

Berdasarkan hasil observasi dan wawancara kepada subjek MT diperoleh bahwa subjek MT sangat menguasai 4 komponen dari kompetensi pedagogik yang diteliti. Subjek MT membuat perangkat pembelajaran dengan baik, mempraktekkan RPPnya dengan baik, penguasaan kelas dan peserta didiknya baik, serta penilaiannya pun dilakukan dengan baik. Artinya subjek MT telah sangat siap untuk mengajar di sekolah bila dilihat dari aspek kompetensi pedagogik. Subjek MS dalam hasil observasi terlihat bahwa dari 4 komponen kompetensi pedagogik, komponen penilaian memiliki nilai terendah. Hal ini pun sejalan dengan hasil wawancara yang menyatakan bahwa subjek MS sangat bingung dalam memahami penilaian di K13. Subjek tidak mengetahui bagaimana instrumen penilaian untuk sikap spiritual dan sosial yang diharapakan di kurikulum 2013 di kelas. Hasil observasi terlihat subjek MR termasuk pada kategori yang siap (menguasai), namun dari segi penilaian terdapat 3 komponen yang rendah. Yaitu komponen pengetahuan kurikulum, pelaksanaan pembelajaran dalam hal ini tidak mengusai model dan strategi pembelajaran yang digunakan, dan penilaian yang sama sekali tidak terlihat pada proses praktek di kelas.

Berdasarkan hasil tersebut menunjukkan bahwa tingkat kemampuan akademik di kelas yang dilihat dari IPK mahasiswa berbanding lurus dengan kemampuan penguasaan kompetensi pedagogiknya. Semakin tinggi IPK seseorang semakin baik pula dia dalam 
mengelola suatu pembelajaran. Hal ini sejalan dengan pendapat Purnomo (2017) yang menyatakan bahwa aspek kognitif dalam hal ini IPK adalah penting untuk menentukan kesuksesan mahasiswa dalam jenjang perkuliahan dan pada gilirannya berguna untuk menuju guru yang sukses. Selain itu menurut Depdiknas (Kaniawati, Utari, \& Suyana, 2007) yang menyatakan bahwa untuk menjadi guru yang professional dalam mengelola pembelajaran, guru/calon guru dituntut memiliki penguasaan bidang studi.

\section{KESIMPULAN}

Tingkat penguasaan kompetensi pedagogik mahasiswa calon guru dalam hal pengembangan kurikulum di sekolah, penyelengaraan pembelajaran di kelas, penguasaan karakteristik peserta didik, pelaksanaan evaluasi pembelajaran rata-rata termasuk ke dalam kriteria menguasai. Subjek yang dipilih berdasarkan tingkat akademiknya memiliki tingkat pengusaan yang berbeda-beda. Tingkat penguasaan kompetensi pedagogik mahasiswa calon guru dengan kemampuan akademik tinggi dalam hal pengembangan kurikulum di sekolah, penyelengaraan pembelajaran di kelas, penguasaan karakteristik peserta didik, pelaksanaan evaluasi pembelajaran rata-rata termasuk ke dalam kriteria sangat menguasai. Tingkat penguasaan kompetensi pedagogik mahasiswa calon guru dengan kemampuan akademik sedang dan rendah dalam hal pengembangan kurikulum di sekolah, penyelengaraan pembelajaran di kelas, penguasaan karakteristik peserta didik, pelaksanaan evaluasi pembelajaran rata-rata termasuk ke dalam kriteria menguasai.

\section{DAFTAR PUSTAKA}

Hakim, A. (2015). Contribution of competence Teacher (Pedagogical, Personality, Professional Competence and Social) on the Performance of Learning. The International Journal of Engineering and sciences (IJES), Volume 4, Issue 2, 1-12.

Kaniawati, Utari, \& Suyana. (2007). Profil kemampuan Mengajar Calon Guru Fisika dalam Program Pengalaman Lapangan (PPL). Jurnal Pengajaran MIPA, Vol.10, No.2, 21-35.

Kurniawan \& Astuti. (2017). Deskripsi Kompetensi Pedagogik Guru dan Calon Guru Kimia SMA Muhammadiyah Semarang. Prosiding Seminar Nasional Pendidikan Sains dan Teknologi Fakultas Matematika dan Ilmu Pengetahuan Alam Universitas Muhammadiyah Semarang, 1-7.

Nugraha. (2013). Penguasaan Kompetensi Pedagogik Mahasiswa Calon Guru dalam Pelaksanaan Program Pengalaman lapangan (PPL). Studi Deskriptif pada Mahasiswa Pendidikan Guru TIK Jurusan Kurtekpend.UPI. Tesis. SPs UPI: tidak diterbitkan.

Paramita, R.P. (2018). Rapor Guru dalam Hasil Uji Kompetensi. Retrieved from Beritaagar. (Online). https://beritaagar.id/artikel-amp/berita/rapor-guru-dalamhasil-uji-kompetensi. [Diakses pada tanggal 4 Februari 2019]. 
Purnomo, Y. W. (2017). Menjadi Guru Matematika: antara Peluang, Harapan, Tuntutan dan Tantangan. Conference Paper disampaikan pada kuliah umum dengan tema "Peran Guru Matematika dalam Persaingan Global" di Program studi Pendidikan Matematika Universitas Muhammadiyah Surakarta, 6 November 2017.

Putri \& Suwatno. (2017). Pengaruh kompetensi Pedagogik dan Kompetensi Sosial terhadap Prestasi Belajar Siswa pada Mata Pelajaran Pengantar Administrasi Perkantoran Kelas X Administrasi Perkantoran di SMKN 1 Subang. Jurnal Pendidikan Manajemen Perkantoran, Vol.1, No.1: 9-18.

Suciu \& Mata. (2011). Pedagogical Competence- the key to Efficient Education. International Online Journal of Education Sciences, 3(2), 411-423. 
84 Deskripsi Kompetensi Pedagogik Mahasiswa Calon Guru pada Mata Kuliah Analisis Kurikulum Matematika 